\title{
Audit of Metabolic Profiles in Women with Turner Syndrome (TS)
}

$\Re$

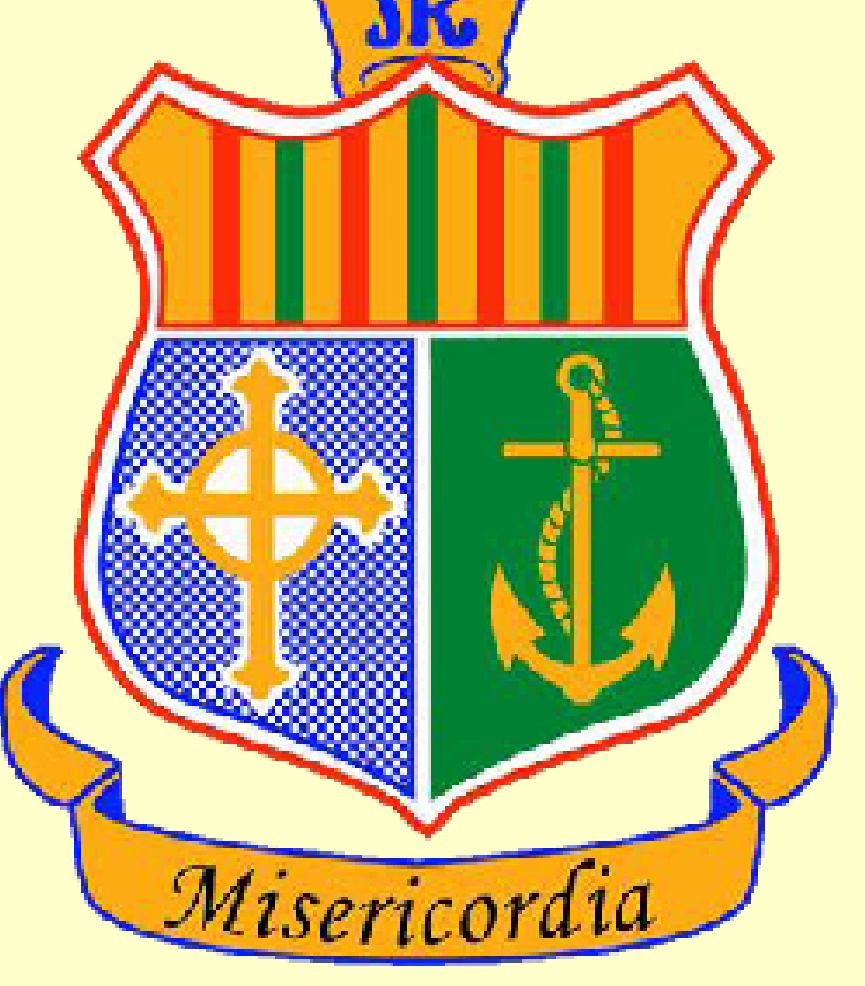

\author{
MP Kyithar, SE McQuaid \\ Department of Endocrinology, Mater Misericordiae University Hospital, Dublin, Ireland
}

\section{OBJECTIVES}

Adults with TS are at increased risk of cardiovascular morbidity and mortality.

The aim of this study was to evaluate the compliance with clinical guidelines in measuring metabolic profiles in adults with TS.

\section{METHODS}

Case notes of patients attending a dedicated TS clinic were studied.

Variables assessed included anthropometric measurements, blood pressure (BP), fasting plasma glucose (FPG), haemoglobin A1c $\left(\mathrm{HbA}_{1 \mathrm{c}}\right)$, fasting lipid profile and thyroid function.

\section{RESULTS}

- Of 40 women with TS, mean age 35.9 years (18-56 years), karyotyping was available on $70 \%$

- $17.5 \%$ had monosomy $(45, X) ; 52.5 \%$ had other $X$ chromosome abnormalities (mosaic $45, X / 46, X X$, ring X chromosome, isochromosome $\mathrm{Xq}$, deletions $\mathrm{Xp}$ and other structural abnormality of $\mathrm{Y}$ chromosome).

- Anthropometric and BP measurements were performed in all patients.

- FPG, $\mathrm{HbA}_{1 \mathrm{c}}$, fasting lipid profile and thyroid function were measured in $90 \%, 82 \%, 92.5 \%$ and $100 \%$ of women, respectively.

- $27.5 \%$ were on antihypertensive medications. $17.5 \%$ were on cholesterol-lowering medications.

- $40 \%$ had primary hypothyroidism on L- thyroxine replacement.

Figures showing distributions of BMI, glucose tolerance, LDL-cholesterol and Triglycerides in women with TS
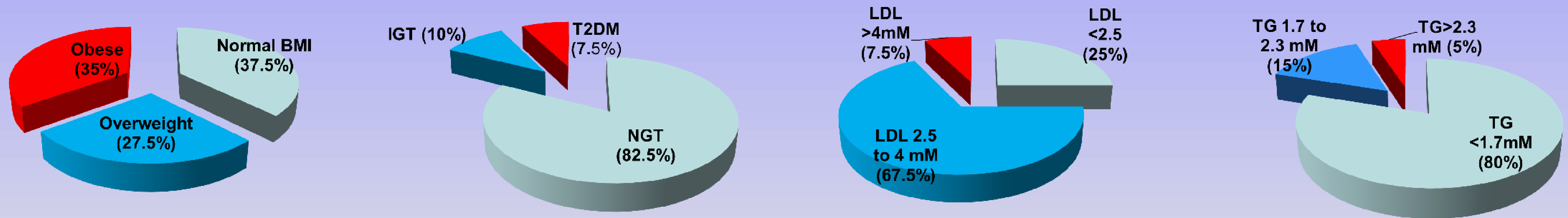

Table showing metabolic profiles of women with monosomy group and those with other $\mathrm{X}$ chromosome abnormalities

\begin{tabular}{|c|c|c|c|}
\hline & $\begin{array}{l}\text { Women with } \\
\text { Monosomy } \\
\text { (mean } \pm \text { SD) }\end{array}$ & $\begin{array}{l}\text { Women with other } X \\
\text { chromosome } \\
\text { abnormalities } \\
\text { (mean } \pm \text { SD) }\end{array}$ & P Value \\
\hline$n$ & 7 & 21 & \\
\hline Age (years) & $40 \pm 7.1$ & $31.2 \pm 10.5$ & 0.05 \\
\hline BMI $\left(\mathrm{kg} / \mathrm{m}^{2}\right)$ & $27.4 \pm 6.1$ & $26.3 \pm 5.2$ & 0.65 \\
\hline SBP $(\mathrm{mmHg})$ & $127.7 \pm 7.2$ & $117 \pm 11.9$ & $0.034^{*}$ \\
\hline DBP $(\mathrm{mmHg})$ & $77.1 \pm 4.6$ & $72.8 \pm 10.2$ & 0.29 \\
\hline $\mathrm{HbA}_{1 \mathrm{c}}(\mathrm{mmol} / \mathrm{mol})$ & $33.7 \pm 3.9$ & $32.7 \pm 2.8$ & 0.52 \\
\hline $\begin{array}{l}\text { Total Chol (mmol/L) } \\
\text { LDL-Chol (mmol/L) } \\
\text { HDL-Chol (mmol/L) } \\
\text { Triglycerides (mmol/L) }\end{array}$ & $\begin{array}{l}5.3 \pm 0.6 \\
2.9 \pm 0.5 \\
1.8 \pm 0.3 \\
1.2 \pm 0.7\end{array}$ & $\begin{array}{l}5.3 \pm 1.1 \\
2.8 \pm 0.7 \\
1.8 \pm 0.5 \\
1.4 \pm 0.8\end{array}$ & $\begin{array}{l}0.92 \\
0.69 \\
0.84 \\
0.64\end{array}$ \\
\hline
\end{tabular}

\section{CONCLUSIONS}

Service evaluation reveals good performance in measuring metabolic parameters in women with TS.

Overweight/obesity, hypertension and dyslipidaemia are common in our group of patients.

Ongoing efforts are aimed at improving these cardiovascular risk factors.

\section{Reference}

Care of girls and women with Turner syndrome: a guideline of the Turner Syndrome Study Group, Bondy et al, J Clin Endocrinol Metab. 2007;92(1):10-25 